\title{
Primary carcinoma of the ureteral stump following radical nephrectomy for renal cell carcinoma: A case report and literature review
}

\author{
SHIHUA JIN, GANG WANG, CHENGFAN YU and NINGCHEN LI \\ Wujieping Urology Center, Peking University Shougang Hospital, Beijing 100144, P.R. China
}

Received February 13, 2015; Accepted February 5, 2016

DOI: $10.3892 / 01.2016 .4426$

\begin{abstract}
The occurrence of primary carcinoma of the ureteral stump following radical nephrectomy for renal cell carcinoma is extremely rare; 7 patients with the disease have been reported previously. All these patients were males with transitional cell carcinoma. The current study reports the case of a 61-year-old woman, who presented with gross hematuria following a radical nephrectomy for local clear cell renal carcinoma. A computed tomography scan revealed the presence of a mass on the ureteral stump. The patient underwent a left ureteral stump and bladder cuff excision. The histological diagnosis was high-grade transitional cell carcinoma of the ureteral stump, with focal interstitial cancer cell infiltrates. There was no evidence of recurrence during a follow-up period of 35 months. In addition, the present study reviewed the literature for previous patients with ureteral stump carcinoma following a radical nephrectomy for renal cell carcinoma; 7 previous patients with the disease were identified. The present study suggests that, if patients who have previously undergone a radical nephrectomy for renal cell carcinoma present with hematuria, the possibility of ureteral stump carcinoma should be considered, particularly in East Asian countries. The existence or a history of bladder carcinoma should be considered as a high-risk factor for developing ureteral stump carcinoma. A ureteral stump and bladder cuff excision should be performed once ureteral stump carcinoma is diagnosed.
\end{abstract}

\section{Introduction}

The incidence of primary carcinoma of the ureteral stump following a simple nephrectomy is quite rare. Kim et al (1) identified that, out of 318 patients who underwent a simple

Correspondence to: Dr Ningchen Li, Wujieping Urology Center, Peking University Shougang Hospital, 9 Jinyuanzhuang Road, Beijing 100144, P.R. China

E-mail: dbh303@aliyun.com

Key words: hematuria, nephrectomy, transitional carcinoma, ureteral stump, renal cell carcinoma nephrectomy for benign renal disease or renal organ donation, 8 presented with ureteral stump carcinoma. Among the 8 patients, 6 patients exhibited transitional cell carcinoma and 2 patients exhibited squamous cell carcinoma. No concomitant bladder tumors were identified at stump tumor diagnosis. Hematuria was the main presenting symptom in 3 of the 8 patients and 4 patients were diagnosed by follow-up imaging studies (1). Ureteral stump carcinomas were typically diagnosed by X-ray and ureteroscopic examination. Excision of the ureteral stump and bladder cuff was performed in 7 patients while radical cystectomy, ureterectomy of the left residual ureter and ileal conduit was performed in 1 patient. Segawa et al (2) reported the 21st case in the Japanese literature of a patient with ureteral stump carcinoma following a simple nephrectomy in 2006. By contrast, primary carcinoma of ureteral stump following a radical nephrectomy for renal cell carcinoma is rare. Previously, 7 patients with the disease have been reported worldwide; and all 7 patients were men with transitional cell carcinoma (3-9). The current study presents a case report of an eighth patient, who is the first female case; and reviews the literature concerning patients with ureteral stump carcinoma following radical nephrectomy. Written informed consent was obtained from the patient.

\section{Case report}

A 61-year-old woman was admitted to Peking University Shougang Hospital (Beijing, China) on 8 March 2012 with asymptomatic intermittent gross hematuria, which had been ongoing for 1 year. The patient had undergone a left radical nephrectomy for local renal carcinoma 2 years prior. The pathological diagnosis 2 years prior was renal clear cell carcinoma, Furhman grade II (10)(Fig. 1), with no evidence of extracapsular extension or regional lymph node metastasis. Following radical nephrectomy, the renal function of the patient was abnormal and serum creatinine (Cre) levels increased to $120-140 \mu \mathrm{mol} / 1$ (normal range, $<98 \mu \mathrm{mol} / \mathrm{l}$ ). The medical history of the patient included hypertension for 3 years prior to the current study. The physical examination of the patient following readmission in March 2012 was unremarkable. Laboratory examinations, including routine blood, urine, liver function and renal function tests, were unremarkable, with the exception of the Cre level of the patient, which was $773 \mu \mathrm{mol} / 1$. Urine cytology was negative. A computed tomography (CT) 


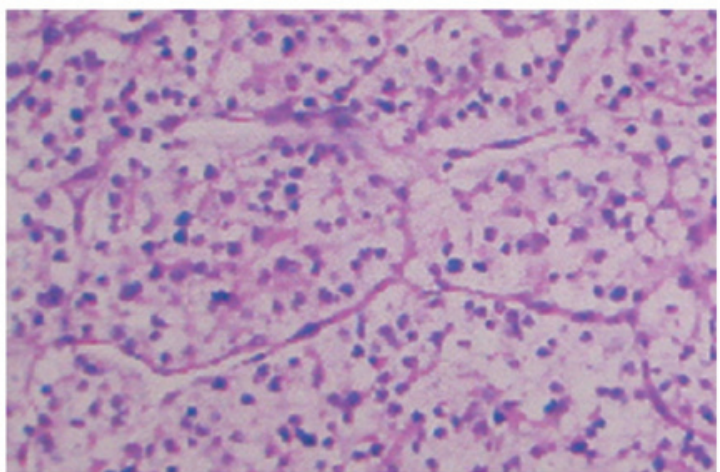

Figure 1. Microscopic examination of the left kidney carcinoma revealing renal clear cell carcinoma, Furhman grade II. Hematoxylin and eosin staining; magnification, x10.



Figure 2. CT scan demonstrating the presence of a $5.0 \times 1.0 \mathrm{~cm}$ solid mass in the left ureteral stump at the site of the iliac artery.

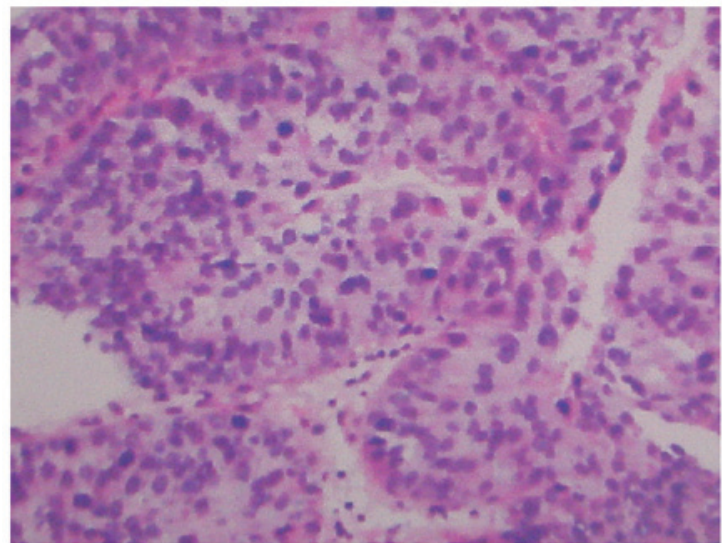

Figure 3. Microscopic examination of the left ureteral stump revealing high-grade urothelial cell carcinoma with focal interstitial infiltrates. Hematoxylin and eosin staining; magnification, $\mathrm{x} 10$.

scan demonstrated the presence of a $5.0 \times 1.0 \mathrm{~cm}$ solid mass in the left ureteral stump at the site of the iliac artery, with no metastasis or invasion (Fig 2). The mean CT value of the mass was $37 \mathrm{HU}$. Hydronephrosis of the right kidney and dilatation of the upper and middle region of right ureter was observed using magnetic resonance hydrography, but the reason for stenosis was unclear. A cystoscopy was performed, which revealed that urine passing through the right ureteral orifice was cloudy and blood was draining from the left ureteral orifice. A double $\mathrm{J}$ stent was placed in the right ureter to drain the urine for 10 days. The Cre level decreased to $300 \mu \mathrm{mol} / \mathrm{l}$ and stabilized. A flexible ureteroscopy was performed on the right-side of the urine collecting system, and a 1-cm stenosis was observed at the lower region of the right ureter. However, there was no sign of a neoplasm of the bladder. Samples were taken from the site of stenosis and the stenosis was dilated with a rigid ureteroscopy. A double $\mathrm{J}$ stent was re-inserted into the right ureter. An excision of the left ureteral stump and bladder cuff was performed. The histological diagnosis following surgery was high-grade transitional carcinoma with focal interstitial cancer cell infiltrates, without invasion of the ureteral muscle layer (Fig. 3). Chronic inflammation was detected in the right ureter, but no carcinoma was observed. The patient did not receive adjuvant therapy following surgery. The patient was alive at the 35-month follow-up; however, the patient possessed chronic renal failure and a double $\mathrm{J}$ stent remained in the right ureter of the patient, which was replaced every 3 months. There was no evidence of recurrence of either renal carcinoma or transitional carcinoma of the urinary tract.

\section{Discussion}

The occurrence of primary carcinoma of the ureteral stump following a simple nephrectomy is rare. Kim et al (1) identified that, out of 318 patients who underwent a simple nephrectomy for benign renal disease or renal organ donation, 8 presented with ureteral stump carcinoma; the incidence rate of the disease was $2.51 \%$. Among the 8 patients, there were 6 patients with transitional cell carcinoma and 2 patients with squamous cell carcinoma (1).

The synchronous occurrence of ipsilateral renal cell carcinoma and urothelial carcinoma in the same kidney is rare (11). Approximately 50 cases of synchronous renal carcinoma and transitional cell carcinoma have been reported in the literature $(12,13)$. Notably, synchronous presentation of both tumors has not been found to result in a worse prognosis $(12,13)$. A small number of cases of synchronous renal carcinoma and ureter carcinoma have also been reported (14-16). Chuang et al (17) reported the case of a 67-year-old woman with renal cell carcinoma and urothelial carcinoma of the bladder, pelvis and ureters.

The occurrence of primary carcinoma of the ureteral stump following a radical nephrectomy for renal cell carcinoma is particularly rare. The present study performed a literature review and, to the best of our knowledge, there were 7 previous cases worldwide of ureteral stump carcinoma following radical nephrectomy for renal cell carcinoma (3-9). All 7 patients presented with transitional cell carcinoma (3-9). The patient described in the current study is the eighth patient with the disease, following transitional cell carcinoma. The previous 7 patients were men, and therefore the present patient is the first female patient reported. The occurrence of ureteral stump carcinoma following radical nephrectomy is markedly lower compared with the occurrence following a simple nephrectomy; however, the reason for this is unclear. From the present literature review, the mean age of patients at diagnosis was 
68.1 years (range, $49-88$ years). The mean interval between the nephrectomy and diagnosis of the ureteral stump carcinoma was 7.3 years (range, 0.9-23.0 years). This is longer than the 6.4-year average interval in patients that underwent a nephrectomy for benign renal disease (1). Among the 8 patients with ureteral stump carcinoma following radical nephrectomy for renal cell carcinoma, 4 patients were from Japan, 1 patient was from China and 3 patients were from Europe and America.

The development of ureteral stump carcinoma may occur due to a number of factors, including the following: Hyperplasia and metaplasia resulting from chronic irritation due to infection or urinary calculi; malignant metamorphosis in urinary leukoplakia; and stimulation by an unrecognized carcinogenic agent (4). However, there was no evidence of significant inflammation or the presence of urinary calculi in the 8 patients with ureteral stump carcinoma following radical nephrectomy for renal cell carcinoma. Haritopoulos et al (9) identified a patient that was first diagnosed with transitional cell carcinoma of the bladder, which was completely resected by transurethral resection. The patient presented with 3 tumor recurrences in the bladder following surgery. In total, 11 years subsequent to the first occurrence of transitional cell carcinoma of the bladder, ureteral stump carcinoma was diagnosed. Among the 8 patients described by the literature review in the present study, bladder carcinoma was concurrent in 2 patients $(6,8)$. In 1 patient, ureteral stump carcinoma was detected by histological examination following radical cystectomy and ureterectomy of the left residual ureter due to the presence of a bladder carcinoma (8). Therefore, a history of prior bladder cancer or concurrent bladder cancer should be considered as a notable risk factor for the development of ureteral stump carcinoma due to the implantation of cancer as a result of vesicoureteral reflux. Regardless of vesicoureteral reflux, the possibility of ureteral stump carcinoma should be considered due to the multifocal development of transitional cell carcinoma of the urinary tract.

The first symptom in all 8 patients identified by the present study was asymptomatic hematuria, including macroscopic hematuria and gross hematuria. Therefore, the ureteral stump must be carefully evaluated when hematuria is observed in a patient following a nephrectomy for renal cell carcinoma. The possibility of ureteral stump carcinoma should not be dismissed, including in cases in which bladder carcinoma has already been diagnosed. Urine cytology may aid diagnosis, but the sensitivity of this method is poor (18). A retrograde ureterogram may reveal a mid-ureteral filling defect. Ureteral stump carcinoma may be identified using a CT scan, which may be enhanced during a contrast enhancement scan. In addition, a ureteroscopy may be used to observe the ureteral stump and to take samples for pathological examination; however, it should be performed with care. A ureteral stump and bladder cuff excision should be performed once ureteral stump carcinoma is diagnosed.

In conclusion, the occurrence of primary carcinoma of the ureteral stump following a radical nephrectomy for renal cell carcinoma is rare. However, if a patient that has undergone a radical nephrectomy possesses hematuria, the possibility of ureteral stump carcinoma should be considered, particularly in East Asian countries. In addition, a history of prior bladder carcinoma or the current existence of bladder carcinoma should be considered as a serious risk factor for the development of ureteral stump carcinoma. A ureteral stump and bladder cuff excision should be performed once ureteral stump carcinoma is diagnosed.

\section{References}

1. Kim YJ, Jeon SH, Huh JS and Chang SG: Long-term follow-up of ureteral stump tumors after nephrectomy for benign renal disease. Eur Urol 46: 748-752, 2004.

2. Segawa N, Kotake Y, Noumi H, Uchimoto S, Azuma H, Katsuoka $Y$ and Tsuji M: Ureteral tumor occurring from remaining stump: A case report. Hinyokika Kiyo 52: 565-567, 2006 (In Japanese).

3. Grey LF, Sorial RF and Levin HJ: Transitional cell carcinoma in ureteral stump after radical nephrectomy for renal cell carcinoma. Urology 29: 209-210, 1987.

4. Suzuki T, Tsuchiya N, Otomo R, Kakinuma H, Satoh S, Sato K, Ogawa $\mathrm{O}$ and Kato T: Primary tumor of the ureteral stump following a nephrectomy for renal cell carcinoma. Int J Urol 6: 41-43, 1999 .

5. Nagatsuma K, Tachibana M, Miyakawa A, Asanuma $H$ and Murai M: Transitional cell carcinoma of ureteral stump after radical nephrectomy for renal cell carcinoma. Int J Urol 6: 627-629, 1999.

6. Cher ML, Milchgrub S and Sagalowsky AI: Transitional cell carcinoma of the ureteral stump 23 years after radical nephrectomy for adenocarcinoma. J Urol 149: 106-108, 1993.

7. Mitsui K, Yamada Y, Taki T, Akahori M, Kato K, Honda N, Fukatsu H, Kawai Y and Yoshikawa K: A case of asynchronous renal cell carcinoma, hepatocellular carcinoma and residual ureteral cancer. Hinyokika Kiyo 44: 583-586, 1998 (In Japanese).

8. Gohji K, Ueno K, Higuchi A and Fujii A: A case of asynchronous renal cell carcinoma and urothelial cancer of the urinary bladder and left ureter. Hinyokika Kiyo 39: 927-930, 1993 (In Japanese).

9. Haritopoulos K, Stravodimos K, Banias C, Giaslakiotis V, Alamanis C and Giannopoulos A: Transitional cell carcinoma of ureteral stump after radical nephrectomy in a patient with a history of bladder carcinoma. Int Urol Nephrol 36: 337-338, 2004.

10. Konety BR and Williams RD: Renal parenchymal neoplasms. In: Smith's General Urology. Tanagho EA and McAninch JW (eds). 17th edition. McGraw-Hill, New York, NY, pp331-332, 2008.

11. Leveridge M,Isotalo PA, Boag AH and Kawakami J: Synchronous ipsilateral renal cell carcinoma and urothelial carcinoma of the renal pelvis. Can Urol Assoc J 3: 64-66, 2009.

12. Fernández Arjona M, Santos Arrontes D, De Castro Barbosa F, Begara Morillas F, Cortes Aranguez I and González L: Synchronous renal clear-cell carcinoma and ipsilateral transitional-cell carcinoma: Case report and bibliographic review. Arch Esp Urol 58: 460-463, 2005 (In Spanish)

13. Mucciardi G, Galì A, D'Amico C, Muscarà G, Barresi V and Magno C: Transitional cell carcinoma of the renal pelvis with synchronous ipsilateral papillary renal cell carcinoma: Case report and review. Urol Case Rep 3: 93-95, 2015.

14. Tsujimura A, Takahara S and Koide T: A case of synchronous ipsilateral renal cell carcinoma and transitional cell carcinoma. Hinyokika Kiyo 37: 1303-1306, 1991 (In Japanese).

15. Merenciano Cortina FJ, Laforga J, De la Morena E, Amat Cecilia M, Rafie Mazketli W and Romero Pérez P: Transitional carcinoma of the ureter and ipsilateral synchronous renal cell carcinoma in hydronephrotic atrophic kidney: Infrequent association. Actas Urol Esp 25: 380-384, 2001 (In Spanish).

16. Ulamec M, Stimac G, Kraus O and Kruslin B: Bilateral renal cell carcinoma and concomitant urothelial carcinoma of the renal pelvis and ureter: Case report. Lijec Vjesn 129: 70-73, 2007 (In Croatian).

17. Chuang HC, Chuang CK and Ng KF: Simultaneous development of renal cell carcinoma and multifocal urothelial carcinoma. Chang Gung Med J 31: 515-519, 2008

18. Flanigan RC: Urothelial tumors of the upper urinary tract. In: Campbell-Walsh Urology. Wein AJ (ed). Vol 2. 9th edition. Saunders Elsevier, Philadelphia, PA, pp1638-1652, 2007. 